\title{
Vigilância sorológica para arbovírus em Juruti, Pará, Brasil
}

\author{
Serological survey for arboviruses \\ in Juruti, Pará State, Brazil
}

\author{
1 Seção de Arbovirologia \\ e Febres Hemorrágicas, \\ Instituto Evandro Chagas, \\ Ananindeua, Brasil. \\ Correspondência \\ A. C. R. Cruz \\ Seção de Arbovirologia \\ e Febres Hemorrágicas, \\ Instituto Evandro Chagas. \\ Rodovia BR 316, Km 7, s.n., \\ Ananindeua, $P A$ \\ 67030-000, Brasil. \\ anacecilia@iec.pa.gov.br
}

\begin{abstract}
This study aimed to measure the prevalence of antibodies to arboviruses in the area affected by the Juruti Project before local mining operations. A total of 1,597 human and 85 wild animal sera were examined, using the hemagglutination inhibition test against 19 antigens from the most prevalent arboviruses in the Brazilian Amazon and IgM-ELISA for dengue and yellow fever. Positive sera for Mayaro and Oropouche viruses were also tested by IgM-ELISA. Prevalence of hemagglutination inhibition antibodies to alphaviruses, flaviviruses, and orthobunyaviruses in humans was 28.7\%, while for wild animals it was $8.2 \%$ for flaviviruses. Recent infections based on presence of IgM was confirmed for Mayaro $(n=5)$, Oropouche $(n=23)$, and dengue $(n=20)$. The results showed active circulation of the dengue, Mayaro, and Oropouche viruses in Juruti, as well as flaviviruses in wild animals, suggesting the circulation of these viruses in the Municipality of Juruti.
\end{abstract}

Serology; Arboviruses; Flaviviridae; Bunyaviridae

\author{
Ana Cecilia Ribeiro Cruz 1 \\ Assis do Socorro Correa dos Prazeres 1 \\ Eliana Colares Gama 1 \\ Maxwell Furtado de Lima 1 \\ Raimunda do Socorro Silva Azevedo ${ }^{1}$ \\ Livia Medeiros Neves Casseb 1 \\ Joaquim Pinto Nunes Neto 1 \\ Lívia Carício Martins 1 \\ Jannifer Oliveira Chiang 1 \\ Sueli Guerreiro Rodrigues 1 \\ Pedro Fernando da Costa Vasconcelos 1
}

\section{Introdução}

As arboviroses em quase sua totalidade são zoonoses mantidas em ambiente silvestre. Conseqüentemente, as pessoas que mantêm contacto com os focos enzoóticos são as que correm maior risco de adquirir a infecção. No entanto, no Brasil, algumas arboviroses têm surgido periodicamente em áreas urbanas, sob forma epidêmica, tais como dengue, Oropouche, Mayaro e Rocio ${ }^{1 .}$

Apesar de estudos intensivos realizados na Amazônia brasileira, sobretudo em certas áreas do Estado do Pará, poucas informações epidemiológicas a respeito da maioria desses vírus foram obtidas, por isso é necessário que pesquisas ecoepidemiológicas sejam realizadas para ampliar o conhecimento científico dos arbovírus já conhecidos, assim como para tentar isolar possíveis novos vírus. $\mathrm{O}$ excessivo desmatamento, a exploração do subsolo, a construção de hidrelétrica, a colonização humana e a urbanização não planejada entre outras, são as principais causas de alterações ambientais introduzidas pelo homem e que têm sido associadas à emergência ou reemergência de arbovírus, inclusive alguns com atividade patogênica para seres humanos 1,2 .

Neste trabalho nos propomos avaliar o ecossistema de parte da área de influência do Projeto Juruti com relação à diversidade de arbovírus circulantes, antes das ações de exploração mineral pelo projeto de mineração de bauxita da empresa ALCOA, mediante análise dos primeiros 
resultados obtidos durante excursões científicas realizadas no período de outubro de 2006 a abril de 2008.

\section{Métodos}

\section{Área do estudo}

O Município de Juruti está situado à margem direita do rio Amazonas, numa área de $8.342 \mathrm{~km}^{2}$ no Estado do Pará, Brasil. A sede municipal tem as seguintes coordenadas geográficas: $02^{\circ} 09^{\prime} 09^{\prime} \mathrm{S}$ e $56^{\circ} 05^{\prime} 42$ ”W Gr. Os locais de captura dos animais silvestres foram nas comunidades Pompom, Capiranga e Ramal Socó (Barroso) em área próxima a São Francisco de Aruã (Figura 1).

\section{Excursões científicas}

Foram realizadas três excursões científicas no período de outubro de 2006 a dezembro de 2007 (vinte dias cada) para coleta de soros de animais silvestres. A captura das aves foi realizada com rede de nylon tipo Netmist, enquanto os roedores e marsupiais foram capturados com armadilhas do tipo Tommhawk (animais de médio porte) e Shermann (animais de pequeno porte).

Os soros de sangue de humanos foram obtidos por punção venosa, na unidade municipal de saúde de Juruti, com base na demanda passiva de pessoas com ou sem sintomas de doença febril, em quatro excursões durante o período, de fevereiro de 2007 a abril de 2008.

\section{Metodologia}

A pesquisa de anticorpos foi realizada no Departamento de Arbovirologia e Febres Hemorrágicas do Instituto Evandro Chagas, utilizando o teste de inibição da hemaglutinação, segundo a microtécnica descrita por Shope em 1963 3, com os soros sendo testados contra antígenos dos arbovírus mais prevalentes na Amazônia.

Para identificação de infecção recente para os vírus da dengue, da febre amarela, Oropouche e Mayaro foi utilizado o método imunoenzimático de captura de IgM (MAC ELISA) conforme descrito por Kuno 4, em 1987, com modificações 5 , e para a detecção de infecção recente para vírus Oropouche e vírus Mayaro foram selecionados apenas os soros com reatividade monotípica ou heterotípica com título maior ou igual a 40 no teste de inibição da hemaglutinação.

\section{Aspectos éticos}

O presente trabalho foi aprovado pelo Comitê de Ética em Pesquisa com Animal do Instituto Evandro Chagas, protocolo $n^{\circ}$. 045/2005, e pelo Comitê de Ética em Pesquisa do Instituto Evandro Chagas, protocolo n ${ }^{\circ}$. 0030/05 (CAAE: 0013.0.072.000-06).

\section{Resultados}

Dos 1.597 soros de humanos obtidos e testados por inibição da hemaglutinação, 671 (41,02\%) apresentaram anticorpos para vírus das famílias Flaviviridae (56,48\%), Bunyaviridae (17,29\%), Togaviridae $(6,11 \%)$ e simultaneamente para as famílias citadas (20,12\%) (Tabela 1). Reações monotípicas (anticorpos para um único vírus) foram observadas para vírus Oropouche $(\mathrm{n}=90)$, vírus Mucambo $(n=13)$, vírus Mayaro $(n=20)$, vírus da dengue $1(n=17)$, vírus Caraparú $(n=8)$, vírus da febre amarela - cepa vacinal 17D $(\mathrm{n}=10)$, vírus Ilhéus ( $\mathrm{n}=15)$, vírus da encefalite Saint Louis $(\mathrm{n}=6)$, vírus Guaroa $(\mathrm{n}=3$ ), vírus da encefalite eqüina do oeste $(n=2)$ e vírus da dengue $2(n=2)$ e outros com menor freqüência (Figura 2).

As 113 e 102 amostras séricas que apresentaram títulos igual ou maior a 40 pelo teste de inibição da hemaglutinação para vírus Oropouche e vírus Mayaro, respectivamente, foram analisadas por ELISA para detecção de anticorpos IgM, e identificadas 23 infecções recentes para vírus Oropouche e cinco para o vírus Mayaro. Análise de captura de IgM para identificação de infecção recente para dengue e febre amarela foram realizadas em todos os 1.597 soros coletados, e encontradas vinte infecções recentes para vírus da dengue e nenhuma para o vírus da febre amarela (Tabela 2).

Dos 85 soros e plasmas de animais silvestres (aves, roedores e marsupiais) testados por inibição da hemaglutinação, 7 (8,2\%) apresentaram anticorpos para os seguintes flavivírus: Cacipacoré, da encefalite Saint Louis, da febre amarela, Ilhéus e Rocio (Tabela 3).

\section{Discussão}

A presença de anticorpos para diversos arbovírus investigados nos animais silvestres e em humanos evidencia, mediante imunidade específica, a circulação desses vírus na área em estudo.

As aves têm sido incriminadas como hospedeira de alguns arbovírus causadores de encefalites, inclusive os pertencentes à família Flaviviridae 2 . Com efeito, a pesquisa de anticorpos 
Figura 1

Mapa da área do estudo na cidade de Juruti, Pará, Brasil.
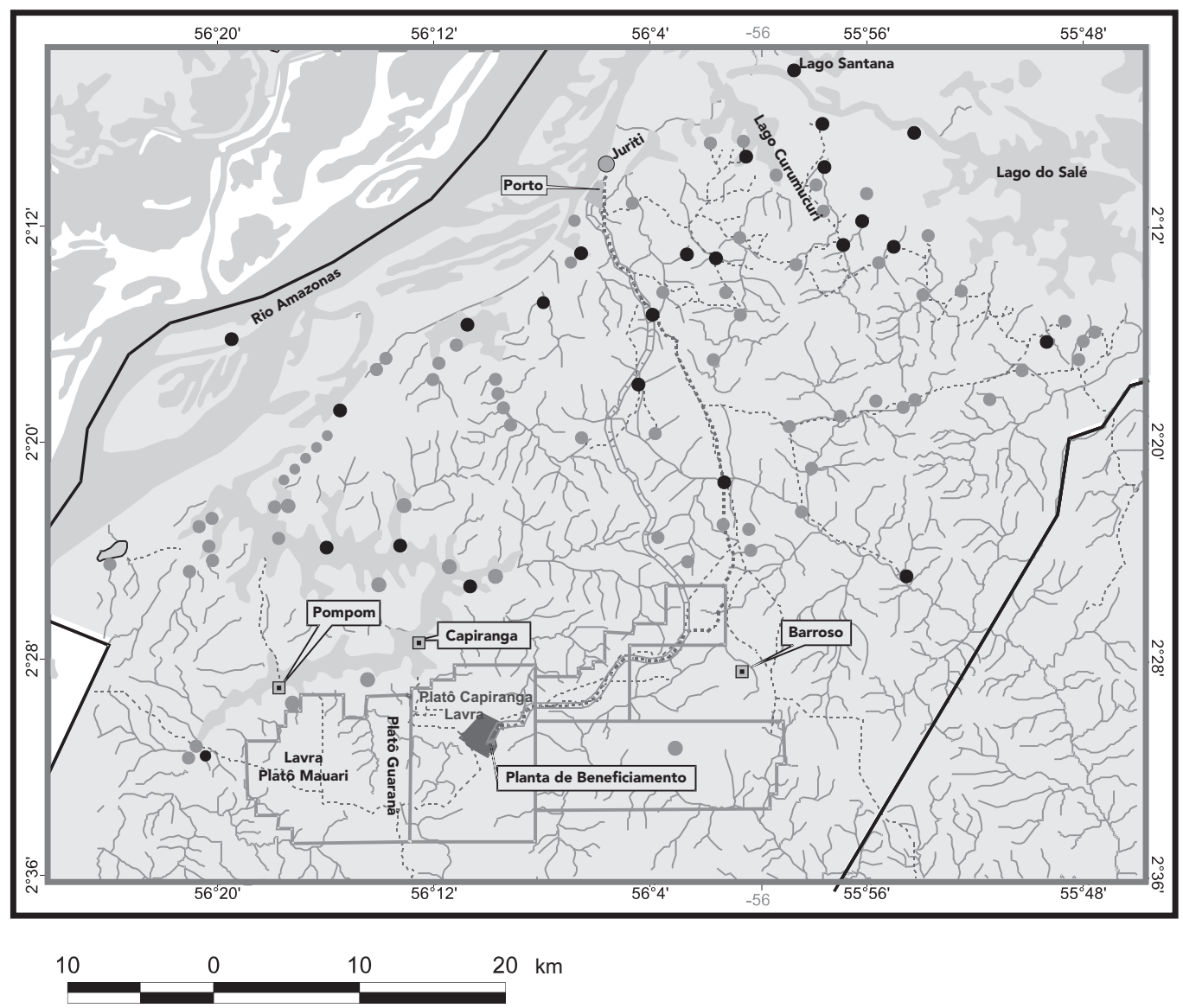

- Locais de captura de animais silvestres

Comunidades

Comunidades pólo

Sede municipal
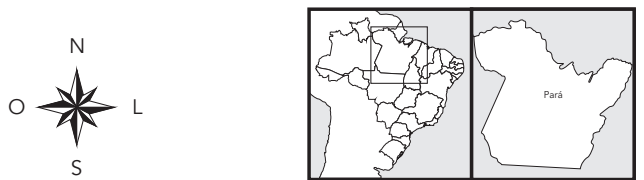

$\therefore \because$ Rodovias

$\therefore$ Vicinais

N Hidrográfia

$\widehat{ }$ Limite municipal

Área de mineração

A Ferrovia

Fonte: Laboratório de Geoprocessamento, Instituto Evandro Chagas. 
Prevalência de anticorpos totais para arbovírus em soros de humanos.

\begin{tabular}{|c|c|c|c|}
\hline \multirow[t]{2}{*}{ Famílias virais } & \multicolumn{2}{|c|}{ Positivos } & \multirow{2}{*}{$\begin{array}{c}\text { Total } \\
\%\end{array}$} \\
\hline & $\mathbf{n}$ & $\%$ & \\
\hline Togaviridae & 41 & 6,11 & 2,57 \\
\hline Bunyaviridae & 116 & 17,29 & 7,26 \\
\hline Flaviviridae & 379 & 56,48 & 23,73 \\
\hline Reações mistas & 135 & 20,12 & 8,45 \\
\hline Togaviridae + Bunyaviridae & 13 & 1,94 & 0,81 \\
\hline Togaviridae + Flaviviridae & 41 & 6,11 & 2,56 \\
\hline Togaviridae + Bunyaviridae + Flaviviridae & 13 & 1,94 & 0,81 \\
\hline Flaviviridae + Bunyaviridae & 68 & 10,13 & 4,28 \\
\hline Positivos & 671 & & 41,02 \\
\hline Negativos & 926 & & 58,98 \\
\hline Total & 1.597 & & \\
\hline
\end{tabular}

Figura 2

Respostas monotípicas detectadas pela presença de anticorpos inibidores da hemaglutinação a partir de soros de humanos.

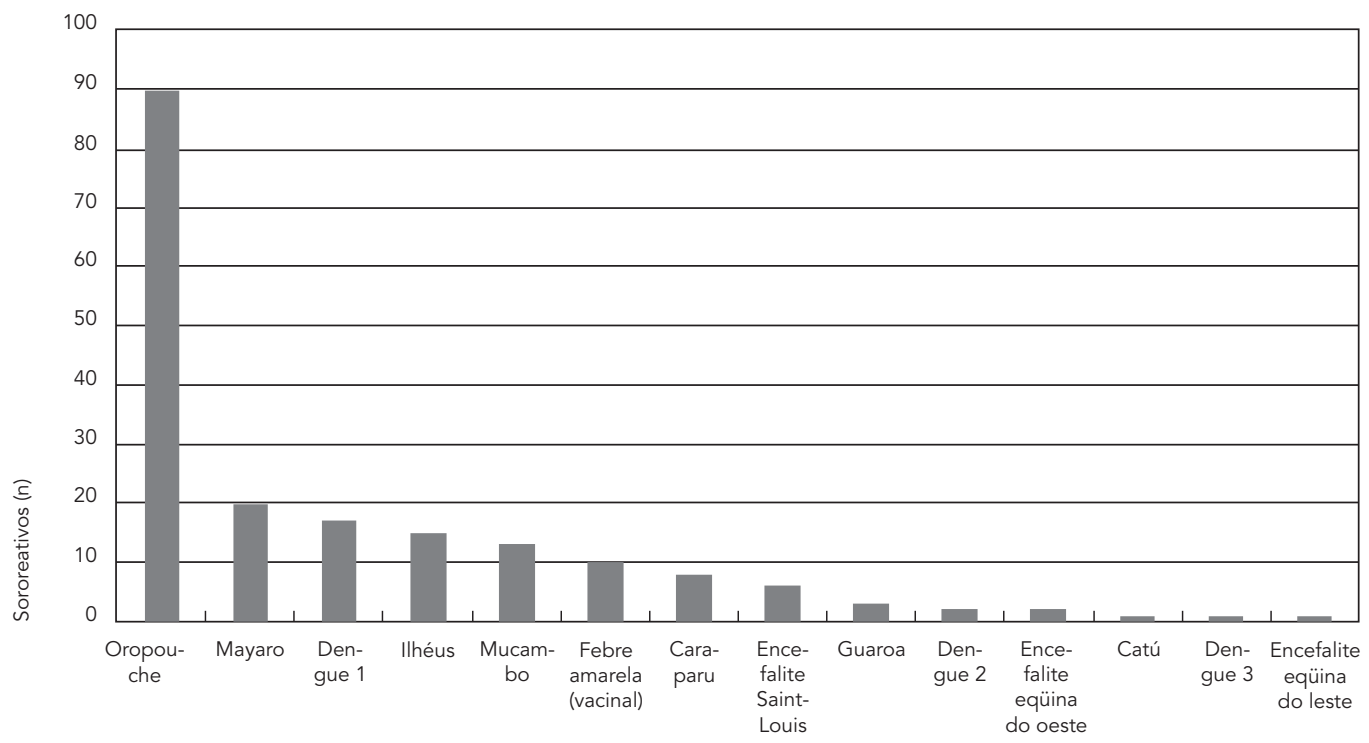

para arbovírus realizada nas aves, demonstrou a presença de anticorpos inibidores da hemaglutinação para vírus da encefalite Saint Louis, vírus Ilhéus e vírus Rocio que são arbovírus causadores de encefalites em humanos e que possuem aves silvestres como principais hospedeiros vertebrados no ciclo silvestre de manutenção 1 .
A detecção de anticorpos da classe IgM anti-Mayaro em cinco amostras de soro humano demonstra a circulação recente desse vírus. $\mathrm{O}$ vírus Mayaro cursa com um quadro febril exantemático acompanhado de artralgias, possui ciclo silvestre de manutenção cujo vetor principal é o mosquito Haemagogus jantinomys, mesmo 
Avaliação sorológica por captura de IgM (MAC ELISA) em soros de humanos.

\begin{tabular}{lcccc}
\hline & Febre amarela & Dengue & Mayaro & Oropouche \\
\hline Positivo & 0 & 20 & 5 & 23 \\
Negativo & 1.597 & 1.577 & 97 & 90 \\
Não testado & 0 & 0 & 1.495 & 1.484 \\
Total & 1.597 & 1.597 & 1.597 & 1.597 \\
\hline
\end{tabular}

Tabela 3

Inquérito sorológico pela presença de anticorpos inibidores da hemaglutinação a partir de soros de animais silvestres.

\begin{tabular}{|c|c|c|c|c|}
\hline Animal & Espécie & Negativos & Positivos & Resultado da inibição da hemaglutinação \\
\hline \multirow[t]{7}{*}{ Aves } & Phlegopsis n. pareensis & 71 & 1 & Vírus Ilhéus, Rocio e encefalite Saint Louis \\
\hline & Geotrygon montana & 0 & 1 & Vírus da febre amarela, Ilhéus, encefalite Saint Louis e Rocio \\
\hline & Thamnophilus aethiops & 0 & 1 & Vírus da febre amarela, Ilhéus, encefalite Saint Louis e Rocio \\
\hline & Conopophaga roberti & 0 & 1 & Vírus da encefalite Saint Louis e Cacicaporé \\
\hline & Schiffornis tudinus & 0 & 1 & Vírus da encefalite Saint Louis \\
\hline & Xiphorhynchus ocellatus & 0 & 1 & Vírus da encefalite Saint Louis \\
\hline & Myrmothera companisona & 0 & 1 & Vírus da encefalite Saint Louis \\
\hline \multirow[t]{2}{*}{ Roedor } & Proechimis guianensis & 2 & 0 & Negativo \\
\hline & Proechimis longicaudatus & 0 & 0 & Negativo \\
\hline \multirow[t]{3}{*}{ Marsupial } & Didelphis marsupialis & 5 & 0 & Negativo \\
\hline & Metachyrus filander & 0 & 0 & Negativo \\
\hline & Didelphis albiventris & 0 & 0 & Negativo \\
\hline Total & & 78 & 7 & \\
\hline
\end{tabular}

transmissor da febre amarela. Este achado indica transmissão ativa do vírus Mayaro em Juruti. Considerando ser o vírus Mayaro causador de doença em humanos sob forma de surtos ou epidemias de febre do Mayaro, é possível que no futuro venham a ocorrer surtos dessa arbovirose em Juruti, uma vez que todos os componentes do ciclo biológico estão presentes na área (vírus Mayaro, transmissores, hospedeiros silvestres e humanos suscetíveis). Por outro lado, a detecção de anticorpos anti-Oropouche da classe IgM em 23 soros de humanos também indica que houve circulação ativa do vírus Oropouche (que causa doença febril) no período do estudo, provavelmente sob forma de um microssurto. É importante assinalar que o vírus Oropouche é, após o vírus da dengue, o arbovírus mais prevalente que infecta humanos, sendo associado com epidemia, e tem como seu transmissor o Culicoides parensis.

A ocorrência do vírus da dengue na Amazônia brasileira é registrada desde 1981 em um surto no
Estado de Roraima 6, todavia sua dispersão para todos os estados da região só ocorreu em 1999. No Município de Juruti não há registro de surtos de dengue antes da detecção de infecção recente dos vintes casos deste estudo. Ressalta-se que os espécimes positivos foram coletados de casos febris no ano de 2008. O registro da ocorrência de dengue em municípios com populações predominantemente rurais é baixo, alguns estudos têm sido realizados no Peru e no Brasil para o entendimento da dinâmica de transmissão de dengue em áreas rurais 7,8 .

Com relação aos demais arbovírus, predominou a presença de anticorpos para flavivírus nos soros examinados (humanos e animais), indicando a já conhecida maior circulação desses vírus como observado em estudos prévios 9,10,11. Os índices elevados de anticorpos contra os flavivírus, alfavírus, orthobunyavírus e as reações mistas indicam a presença constante de arboviroses na população do Município de Juruti (Tabela 1). É muito importante que a vigilância des- 
sas arboviroses seja constante, em decorrência do aumento populacional e ocupação desordenada, que emergiu por causa da implantação do projeto de exploração mineral nesse município prevista para ocorrer em breve.

Com base nos resultados parciais obtidos, é possível que no futuro próximo ocorram epidemias causadas por arbovírus de importância em saúde pública, tais como dengue, Mayaro, Oropouche e outros. Portanto, estudos longitudinais com acompanhamento das populações expostas nas áreas próximas à implantação do projeto de exploração mineral devem ser realizados. Finalmente, tais estudos poderão fornecer informações adicionais para um melhor entendimento dos mecanismos de transmissão, ciclos de manutenção em natureza e dinâmica da circulação dos arbovírus na região, em especial no Município de Juruti.

\section{Resumo}

O objetivo foi avaliar a prevalência de anticorpos para arbovírus na área de influência do Projeto Juruti antes da exploração mineral local. Foram examinados 1.597 soros humanos e 85 de animais silvestres. A pesquisa de anticorpos foi realizada pelo teste de inibição da hemaglutinação contra antígenos dos arbovírus mais prevalentes na Amazônia brasileira e IgM-ELISA para dengue e febre amarela. Soros humanos inibidores da hemaglutinação positivos para Mayaro e Oropouche foram também testados por IgM-ELISA. Anticorpos inibidores da hemaglutinação para alfavírus, orthobunyavirus e/ou flavivírus foram detectados, sendo $28,7 \%$ reações monotípicas. Infecções recentes para Oropouche $(n=23)$, Mayaro $(n=5)$, e dengue $(n=20)$ foram confirmadas por IgM-ELISA. A prevalência de anticorpos inibidores da hemaglutinação em soros de animais silvestres foi de 8,2\% para flavivírus. Os resultados obtidos mostram que houve circulação ativa dos vírus Mayaro, Oropouche e dengue no período do estudo em humanos em Juruti, Pará, Brasil, e de diversos arbovírus em animais silvestres, indicando presença desses vírus em áreas do Município de Juruti.

Sorologia; Arbovírus; Flaviviridae; Bunyaviridae

\section{Colaboradores}

A. C. R. Cruz e P. F. C. Vasconcelos participaram da concepção do desenho, da obtenção e análise de dados, elaboração e revisão crítica do artigo. A. S. C. Prazeres, E. C. Gama, M. F. Lima e J. P. Nunes Neto e colaboraram na aquisição dos dados e elaboração do artigo. R. S. S. Azevedo participou do levantamento e análise de dados, elaboração e revisão do artigo. L. M. N. Casseb colaborou na preparação do artigo e na sua revisão crítica. L. C. Martins participou da aquisição, levantamento e análise de dados, elaboração e revisão do artigo. J. O. Chiang colaborou na aquisição, levantamento e análise de dados e revisão do artigo. S. G. Rodrigues contribuiu na concepção do desenho, da obtenção dos dados e elaboração do artigo.

\section{Agradecimentos}

Agradecemos aos técnicos: Hélio Saraiva, Luiz R. Oliveira, Basílio Buna, Orlando Vaz, Osvaldo Vaz, Ercília Gonçalves, Raimundo L. dos Anjos, Francisco Castro e Iveraldo da Silva que participaram do trabalho de campo. Ao Sr. Douglas Gasparetto pela preparação do mapa vetorial. Agradecemos o apoio financeiro da empresa ALCOA, Instituto Evandro Chagas e Conselho Nacional de Desenvolvimento Científico e Tecnológico (CNPq, processo $n^{\circ} .300460 / 2005-8$ - bolsa de produtividade em pesquisa). Agradecemos ainda o apoio logístico da Secretaria Municipal de Saúde de Juruti. 


\section{Referências}

1. Travassos-da-Rosa AP, Travassos-da-Rosa JF, Pinheiro FP, Vasconcelos PFC. Arboviroses. In Leão $\mathrm{RN}$, organizador. Doenças infecciosas e parasitárias: enfoque amazônico. Belém: Editora CEJUP/ Universidade do Estado do Pará; 1997. p. 208-25.

2. Vasconcelos PFC, Travassos-da-Rosa AP, Rodrigues SG, Travassos-da-Rosa ES, Dégallier N, Travassosda-Rosa JF. Inadequate management of natural ecosystem in the Brazilian Amazon region results in the emergence and reemergence of arboviruses. Cad Saúde Pública 2001; 17 Suppl:155-64.

3. Shope RE. The use of a microhemagglutinationinhibition test to follow antibody response after arthropod-borne virus infection in a community of forest animals. An Microbiol (Rio J.) 1963; 11 (Pt A):167-71.

4. Kuno G, Gomez I, Gubler, DJ. Detecting artificial antidengue IgM immune complexes using an enzymelinked immunosorbent assay. Am J Trop Med Hyg 1987; 36:153-9.

5. Vasconcelos PFC, Travassos-da-Rosa JF, Guerrero SG, Dégallier N, Travassos-da-Rosa ES, Travassosda-Rosa AP. Primeiro registro de epidemias causadas pelo vírus Oropouche nos estados do Maranhão e Goiás, Brasil. Rev Inst Med Trop São Paulo 1989; 31:271-8.
6. Travassos-da-Rosa AP, Rocha JM, Silva OV, Lins ZC Surto de dengue em Boa Vista, território de Roraima, Brasil. Bol Epidemiol (Rio J.) 1982; 14:93-104.

7. Hayes CG, Phillips IA, Callahan JD, Griebenow WF, Hyams KC, Wu SJ, et al. The epidemiology of dengue virus infection among urban, jungle, and rural populations in the Amazon region of Peru. Am J Trop Med Hyg 1996; 55:459-63.

8. Silva-Nunes M, Malafronte RS, Luz BA, Souza EA, Martins LC, Rodrigues SG, et al. The Acre Project: the epidemiology of malaria and arthropod-borne virus infections in a rural Amazonian population. Cad Saúde Pública 2006; 22:1325-34.

9. Pinheiro FP, Bensabath G, Travassos-da-Rosa AP, Lainson R, Shaw JJ, Fraiha H, et al. Public health hazards among workers along the Trans-Amazon Highway. J Occup Med 1977; 19:490-7.

10. Dégallier N, Travassos-da-Rosa AP, Vasconcelos PFC, Hervé JP, Sá Filho GC, Travassos-da-Rosa ES, Rodrigues SG. Modifications of arboviruses transmission in relation to construction of dams in Brazilian Amazon. Ciênc Cult (São Paulo) 1992; 44:124-35.

11. Travassos-da-Rosa AP, Travassos-da-Rosa JF, Hervé JP, Vasconcelos PFC, Dégallier N, Rodrigues SG. Arboviruses in Serra Norte, Carajás Region, Pará, Brazil. Ciênc Cult (São Paulo) 1992; 44:158-61.

Recebido em 14/Jan/2009

Versão final reapresentada em 16/Jul/2009

Aprovado 29/Jul/2009 